\title{
Alphonse Daudet pluriel et singulier, textes réunis et présentés par Christian Chelebourg
}

\section{Philippe Andrès}

\section{(2) OpenEdition}

1 Journals

\section{Édition électronique}

URL : http://journals.openedition.org/studifrancesi/35016

DOI : 10.4000/studifrancesi.35016

ISSN : 2427-5856

Éditeur

Rosenberg \& Sellier

\section{Édition imprimée}

Date de publication : 1 novembre 2005

Pagination : 439

ISSN : 0039-2944

\section{Référence électronique}

Philippe Andrès, «Alphonse Daudet pluriel et singulier, textes réunis et présentés par Christian

Chelebourg ", Studi Francesi [En ligne], 146 (XLIX | II) | 2005, mis en ligne le 30 novembre 2015, consulté le 20 avril 2021. URL : http://journals.openedition.org/studifrancesi/35016 ; DOI : https:// doi.org/10.4000/studifrancesi.35016

\section{Ce document a été généré automatiquement le 20 avril 2021.}

\section{(c) (i) $\odot$}

Studi Francesi è distribuita con Licenza Creative Commons Attribuzione - Non commerciale - Non opere derivate 4.0 Internazionale. 


\title{
Alphonse Daudet pluriel et singulier, textes réunis et présentés par Christian Chelebourg
}

\author{
Philippe Andrès
}

\section{RÉFÉRENCE}

AA. VV. «Ecritures XIX ${ }^{\mathrm{e}} 1 »$, Alphonse Daudet pluriel et singulier, rencontres de Cerisy-laSalle (14-21 août 2002), textes réunis et présentés par CHRISTIAN CHELEBOURG, Lettres modernes Minard, Paris-Caen, 2003, pp. 334.

1 Le colloque de Cerisy consacré à Alphonse Daudet souligne la diversité de l'œuvre d'un auteur trop souvent cantonné dans une image stéréotypée scolaire et solaire. La première partie de l'ouvrage collectif se consacre à l'Esthétique daudétienne. AnneSimone DufIEF («Alphonse Daudet: roman, théâtre», pp.13-29) s'interroge sur la rivalité entre roman et théâtre à la fin du XIX siècle, sur l'échec des transpositions théâtrales de romans réalistes. Daudet, chroniqueur dramatique du Journal officiel, dissocie théâtre et leçons de morale, souligne l'infériorité du théâtre par rapport au roman, se déclare partisan d'un théâtre poétique, véritable enjeu esthétique du théâtre à la fin du siècle. Henri Rossi («Alphonse Daudet à l'Opéra, 1: Daudet sur la scène lyrique», pp. 31-48) analyse brièvement l'aspect méconnu d'un Daudet librettiste et s'attarde sur le succès de Sapho, pièce lyrique en cinq actes transposée du roman de Daudet. Stéphane LE COUEDIC («Jeunesse de Daudet: poésie et abandon?», pp. 49-66) s'interroge sur le rôle non négligeable de l'œuvre poétique de jeunesse, notamment le recueil des Amoureuses - poèmes et fantaisies (1857-1861). Puis Françoise COURT-PEREz présente les «Figures de l'ironie chez Daudet» (pp.67-81) qui n'excluent pas la fantaisie dans le rapport à l'Institution (L'Immortel), sans pour autant tomber dans le moralisme. Angels RIBES démontre que le cliché concernant la réception de l'œuvre de Daudet vaut également 
pour la Catalogne («La Réception et les traductions d'Alphonse Daudet dans les lettres catalanes», pp. 83-94).

2 En ouverture au second volet consacré à la topique, Roger RIPOLL démonte les mécanismes de l'illusion puisque «l'effet de réalité est recherché dans un perpétuel papillotement» («L'Illusion dans l'univers de Daudet», pp. 97-106). Pour sa part, Jérôme SolAL s'interroge sur le lien entre maladie honteuse et nerveuse en abordant la délicate question de la névrose («L'Heure de la douleur, La Doulou d'Alphonse Daudet», pp. 107-122). Il revient à Jean-Paul Colin de présenter, non sans humour «La Mort, cette petite chose» (pp.123-137), surtout comme figure de rhétorique». Nicholas WHITE («Comment écrire le roman du divorce?, à propos de Rose et Ninette», pp.139-154) s'intéresse à un roman méconnu et au rôle de la loi d'Alfred Naquet de 1884 sur le divorce. De nouveau Henri Rossi nous entretient d' «Alphonse Daudet à l'Opéra, 2: la scène lyrique chez Daudet» (pp.155-172). Il s'agit de montrer le jeu complexe des interférences entre écriture romanesque et la scène lyrique présentes passim dans l'œuvre. Myriam KISSEL, pour sa part, dans «Tartarin sur les Alpes - humour et nihilisme: l'aporie de la conquête» (pp.173-187) souligne le double intérêt du roman qui met en scène l'actualité des mouvements révolutionnaires russes et l'essor du tourisme alpin. Finalement, Hervé GUINERET nous présente un Daudet non doctrinaire bien qu'opposé à la République, et quelque peu pessimiste dans son analyse de la société française («L'Attitude politique d'Alphonse Daudet: Les Rois en exil», pp. 189-204)).

3 La troisième partie (consacrée à la «Poétique») s'ouvre sur un texte de Pierre DufiEf qui nous interpelle sur les différentes facettes de «Daudet, le marchand de bonheur» (pp. 207-222). En effet, l'acuité des sens souligne que l' «état de bonheur» ancré dans l'ontologique s'ouvre sur des projections de type fusionnel où la fantaisie joue un rôleclé. On est loin cependant de l'exaltation romantique, même si tout bonheur s'accompagne de son contraire. Dans sa communication sur «La Vérification des pouvoirs: à propos du "style artiste" chez Alphonse Daudet» (pp. 223-239), Serge METTINGER tente une analyse idéologique concernant le rapport entre pouvoir et sensation. Maryse PETIT, quant à elle, propose une réflexion sur «Daudet terre à terre: l'écriture naturaliste» (pp. 241-258), soulignant la complexité de la tentation de l'autoanalyse. Bernard URBANI («Espace et récit dans Sapho d'Alphonse Daudet», pp. 259-273) montre que l'espace romanesque se transforme en intériorité. Puis André NoT s'intéresse au thème de la porte dans «Les Portes du Petit Chose ou du danger des grandes aventures» (pp. 275-291). Retenons la communication de Philippe ORTEL sur «Alphonse Daudet et les images sensibles» (pp. 293-309). L'image se transforme en modèle critique dans un réseau analogique où le regard joue un rôle «iconisant» au coeur de «l'imagerie comme dispositif». Finalement Christian CheLebourg souligne le rapport ambivalent entre Daudet et le naturalisme zolien; il rappelle l'influence du vérisme italien et propose une réflexion sur une poétique de la myopie qui vient briser la conception d'une vérité objective, impossible à circonscrire dans le champ du littéraire («Mensonge naturaliste et vérité myope: poétique et vérité chez Alphonse Daudet», pp. 311-327).

4 Faire lire dans sa complexité, en dehors de tout cliché, l'œuvre de Daudet: tel est donc l'objectif atteint par cet ouvrage. 